\title{
O ENSINO DA LINGUAGEM ORAL: DA ACADEMIA À \\ EDUCAÇÃO BÁSICA - PRÁTICA POSSÍVEL?
}

\author{
Adriana Carvalho Souza Castro ${ }^{1}$ \\ Adelma das Neves Nunes Barros-Mendes ${ }^{2}$ \\ Juliana da Costa Castro ${ }^{3}$
}

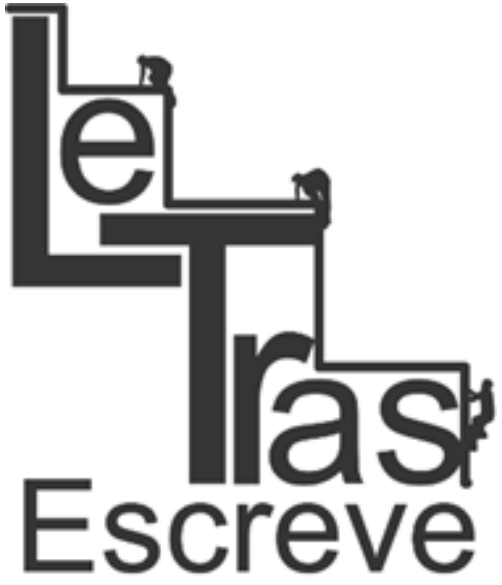

(ISSN 2238-8060)

RESUMO: Com o advento dos Parâmetros Curriculares Nacionais (PCN), se trouxe para a escola brasileira, no que diz respeito ao ensino da Língua Materna, não objetos de ensino novos, mas olhares e interpretações resignificados desses objetos como a linguagem oral. Considerando a reivindicação desse objeto para ser ensinado nas escolas o foco da investigação aqui refletida, se fez sobre os Projetos Pedagógicos de Curso (PPC) do curso de Licenciatura em Letras de 39 Instituições de Ensino Superior com o objetivo de construir um mapa do trabalho com oral e a partir dele compreender as concepções que circulam na academia acerca do ensino desse objeto. Metodologicamente, amparados na pesquisa em Linguística Aplicada, lançamos mão da perspectiva do Paradigma indiciário (GINSBURG, 1992; BRAIT, 2002), realizando um levantamento em sites de diversas universidades públicas e privadas verificando-se os PPC dos cursos de Letras. Desse levantamento mapeou-se 39 PPC de Letras, assim, como resultado verificou-se que há perspectivas diversas acerca do tratamento com a linguagem oral, tal análise permitiu uma maior reflexão sobre as possíveis causas da fragilidade desse objeto na educação básica.

Palavras-chave: oralidade; PPC's; objeto de ensino.

RÉSUMÉ: Avec l'avènement des Parâmetros Curriculares Nacionais (PCN), a été amené à l'école brésilienne, en quoi se réfère l'enseignement de la langue maternelle, pas de nouveaux objets d'apprentissage, mais il semble et des nouvelles interprétations de ces objets comme la langue orale. Compte tenu de l'affirmation selon laquelle l'objet à enseigner dans les écoles au centre de recherche ici reflète, il a été fait sur Le Projet Pédagogique du Cours (PPC) des Cours de Lettres de 39 établissements d'enseignement supérieur pour construire une carte de travail avec l'oral et d'en comprendre les conceptions qui circulent dans l'académie sur l'enseignement de cet objet. recherche soutenue méthodologiquement en Linguistique Appliquée, nous avons utilisé la perspective du Paradigme de Indiciary (Ginsburg, 1992; BRAIT, 2002), la réalisation d'une enquête sur les sites Web des différentes universités publiques et privées du PPC de vérification des cours de Lettres.

\footnotetext{
1 Professora Especialista da Rede Pública do Estado do Amapá; e-mail: adrianacarvaIhoss@yahoo.com.br

2 Professora Doutora da Universidade Federal do Amapá; e-mail: adelma@unifap.br

${ }^{3}$ Professor Especialista da Universidade Federal do Amapá; e-mail: juliana@unifap.br
} 
Cette enquête cartographié à 39 Lettres de PPC, ainsi que par conséquent, il a été constaté qu'il ya des points de vue différents sur le traitement avec la langue orale, cette analyse a permis une plus grande réflexion sur les causes possibles de la fragilité de cet objet dans l'éducation de base.

Mots-clés: oralité; PPC's; objet d'enseignement.

\section{INTRODUÇÃO}

O destaque dado à linguagem oral nos últimos anos, sobretudo provocado pelas orientações dos documentos oficiais, como os Parâmetros Curriculares Nacionais voltados ao Ensino Fundamental e Médio, tem provocado inquietações por parte de pesquisadores, professores, sobretudo os que atuam na área de ensino de língua Portuguesa. No entanto, não podemos deixar de considerar, como aponta Barros-Mendes (2005), que se trata de um objeto cuja preocupação é antiga, visto que tradicionalmente, nas disciplinas Retórica e Poética, a linguagem oral era bastante valorizada nas salas de aula, nos exercícios de elocução e de recitação de poemas.

Em outros termos, é um objeto que sempre esteve nas propostas de ensino de língua materna. Assim, quando se analisa o percurso de ensino da Língua Materna (LM), verifica-se que apesar da percep-

(ISSN 2238-8060)

ção histórica acerca da importância e lugar que esse objeto deva ocupar na sala de aula, não houve de fato sua concretização, nesses mais de dois séculos de institucionalização do ensino da Língua Portuguesa no Brasil. Essa ideia é comprovada quando, ao analisar os documentos oficiais, principalmente a partir de 1998, percebe-se que a linguagem oral é retomada como algo "novo".

Assim, a partir dos anos 1998, o ensino da linguagem oral ganha novamente destaque, em especial nas publicações oficiais, como os PCN - Ensinos Fundamental e Médio (1997; 1998; 2000), Orientações Curriculares Nacionais (2006), Guias e Catálogos de escolha de livros didáticos de toda educação básica etc, bem como nas publica- 
ções e reedições de livros didáticos de LM, que autores e editores passaram a dar maior atenção a esse objeto nos exercícios e atividades dos livros que entrariam nas salas de aula das escolas públicas brasileiras.(Cf. Rojo, 2004; Barros Mendes, 2005; Gomes, 2010).

Considerando-se quase duas décadas das novas orientações acerca da necessidade de se trabalhar a linguagem oral como objeto a ser ensinado, considerando ainda o reconhecimento desse objeto para a realidade atual, global e altamente tecnológica, onde as interações se tornaram não somente dinâmicas e céleres, mas com limites tênues entre as fronteiras público $\mathbf{x}$ privado, é que, neste texto, busca-se mapear e compreender como a academia, em especial nos cursos de licenciatura em Letras, concebe esse objeto e de que forma prepara os acadêmicos, futuros professores, para tratá-lo em sala de aula.

Embora se reconheça tratar-se de um objeto que atravessa todas as áreas do conhecimento, no campo das licenciaturas, espera-se que sejam os cursos de Letras e Pedagogia os responsáveis pela formação dos professores que devam tratar desse objeto na educação básica. O primeiro muito mais fortemente exigido, por abarcar todo (ISSN 2238-8060) esse nível de educação; o segundo pela formação inicial que lhe cabe, é nesse prisma, que o foco da investigação aqui refletida, se fez sobre Projetos Pedagógicos de Curso (PPC) do curso de Letras de diversas Instituições de Ensino Superior (IFES) do país. Para se obter um mapa e compreender as concepções acerca do ensino do oral, realizou-se um levantamento em sites de diversas universidades públicas e privadas.

Papel da linguagem oral como objeto de ensino, segundo os documentos oficiais

Em se tratando dos Parâmetros Curriculares Nacionais $3^{\circ}$ e $4^{\circ}$ 


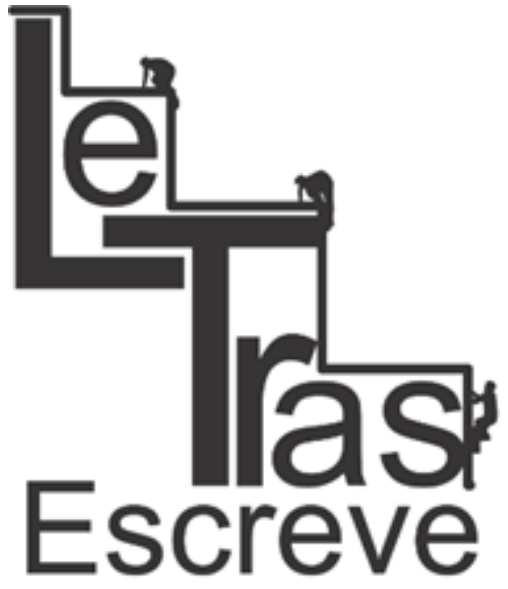

(ISSN 2238-8060) ciclos, defende-se que no âmbito escolar o aluno deve ser preparado para utilizar a linguagem oral no planejamento e na realização dos gêneros do discurso afins como debates, entrevistas, seminários, palestras, por exemplo, promovendo situações em que essas atividades estejam contextualizadas com sua prática e função social, pois considera que a razão de ser das propostas de uso da fala é a "interlocuçãoefetiva" (MEC, 1998, p.19) adequada às condições de produção e de recepção dos diferentes eventos comunicativos, deixando de lado a prática de elaboração de textos para serem objetos de correção gramatical. Mantendo-se assim, concepções de língua como prática discursiva.

Seguindo esse pressuposto, os PCN+ (2002) trazem forte preocupação em estabelecer uma ligação entre a teoria bakhtiniana com o fazer pedagógico do professor formador de sujeitos letrados, ou como diz Bortoni-Ricardo et al., (2012) pelo profissional caracterizado como agente de letramento. Por isso, para os documentos oficiais é fundamental que a escola "abra espaço para diferentes abordagens do conhecimento. Desse modo, ainda que a palavra escrita ocupe um espaço privilegiado na disciplina, é possível que a produção de textos falados ganhe uma sistematização" (PCN+, 2002, p.71) por meio dos gêneros orais formais públicos, e mesmo os do cotidiano como a conversa espontânea, são instrumentos comunicativos que servem para controlar a comunicação e os discursos que por ela permeiam.

Essas reflexões são ainda defendidas pelas Orientações Curriculares Nacionais OCENEM (2006, p.37), quando explicam que

por meio desse tipo de expediente, pode-se não só contribuir para a construção e a ampliação de conhecimentos dos alunos sobre como agir nessas práticas, como também promover um ambiente profícuo à discussão e à superação de preconceitos linguísticos e, sobretudo, à investigação sobre as relações entre os gêneros da oralida- 
de e da escrita, sobre a variação linguística, sobre níveis de formalidade no uso da língua, por exemplo.

Como forma de orientar para que essas reflexões se concretizem na prática escolar, destaque-se que a escola precisa promover situações de interações dialogais que levem em consideração que os alunos já dispõem de competências linguísticas e discursivas, sendo assim, capazes de manter relações sociais viáveis para a construção de conhecimentos por meio de "trocas de informação, confronto de opiniões, negociação de sentidos"sempre visando a um sujeito competente linguisticamente para o pleno exercício da cidadania (PCN,1998, p.41).

Essa competência linguística implica, por exemplo, na defesa de seus direitos e opiniões, ou ainda, na capacidade de atender as exigências de adequação às características próprias de diferentes gêneros. Nesse sentido ratifica-se que o registro formal não pode ser tomado como apropriado à todas as situações de fala, pois, como já dito, cada gênero oral exige implicações contextualizadas social e historicamente.

As OCNEM (2006) primam pela inserção do aluno em esferas (ISSN 2238-8060) de atividades diversificadas como: literária, científica, publicitária, religiosa, jurídica, burocrática, cultural, política, econômica, midiática, esportiva; seguindo a ideia de Marcuschi (2011, p.20) "o enunciado ou discurso não é um ato isolado e solitário, nem na oralidade nem na escrita", assim o ensino do oral deve ser imbuído desse pressuposto dialógico.

Nesse ponto, esses os documentos oficiais propõem que o trabalho com a oralidade opere em dois âmbitos: o da escuta e o da produção de textos orais. O primeiro deve ampliar progressivamente conhecimentos envolvidos na construção do sentido do texto, tais como a percepção de elementos não verbais (expressão facial, ges- 
tos), o reconhecimento das intenções do enunciador, e ainda, a utilização da linguagem escrita, sempre que necessário, como apoio para o registro, documentação e análise.

E no âmbito da produção, as atividades devem aliar o planejamento da fala ao da escrita em função da intenção do locutor, das características do receptor e dos objetivos estabelecidos; ou seja, preparando o aluno para situações reais de interlocução, proporcionando-Ihe conhecimento pratico e teórico adequado para uma efetiva participação social, capazes de usufruírem da linguagem de forma critica, responsiva e consciente.

Como se vê, apesar de o oral vir sendo reivindicado há tempos

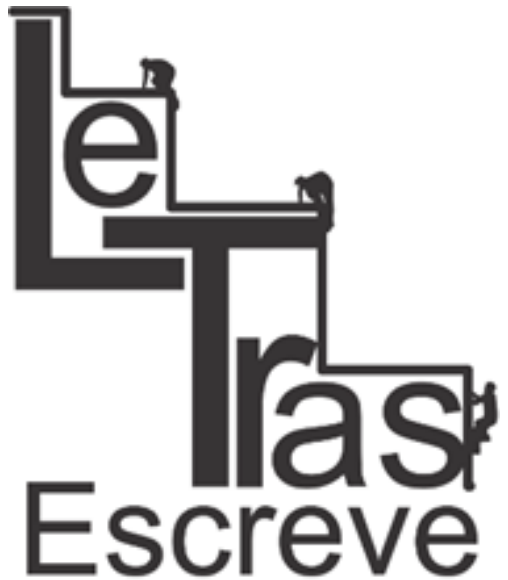

(ISSN 2238-8060) no Brasil, com especial atenção, nos documentos oficiais, ainda sabese muito pouco sobre a realidade do seu trabalho em sala de aula de forma efetiva, da mesma forma pouco se tem acerca de pesquisas que apontem filiações a alguma corrente a que estejam ligadas as propostas desse ensino. Somando-se a isso, questionamentos acerca da importância do trabalho com a oralidade em sala de aula ainda permeiam as práticas escolares, trazendo consigo dúvidas sobre a real necessidade do ensino desse objeto. Essa realidade reforça e justifica a importância do estudo aqui proposto.

\section{Abordagens sobre a linguagem oral}

Barros Mendes (2005), amparada em estudos feitos por Schneuwly et al. (1997), traz para essa reflexão a discussão acerca de duas abordagens sobre o trabalho com o oral. A primeira atua dentro da perspectiva que se concebe a linguagem oral como objeto integrado de ensino e tem por princípio a possibilidade de se desenvolver as capacidades dos alunos, apoiando-se sobre situações múltiplas que se apresentam na sala de aula. 
Priorizando-se a dinâmica das trocas no momento da aprendizagem, o oral passa a ser um mediador privilegiado de conhecimentos e de desenvolvimento intelectual. Isso se dá graças a variedade funcional e a riqueza das relações verbalizadas que permeiam uma atividade em sala de aula, que exigem uma diversificação de papeis e de condutas, enriquecendo as formulações (sustentações do que se pensa, confrontações e justificações, hipóteses).

A segunda abordagem parte do princípio de que ensinar a linguagem oral significa desenvolver o domínio de diversas situações de comunicação pública (trabalho, escola, administração, política), pela apropriação de gêneros que circulam nessas situações. Em outros termos, são as formas institucionalizadas da linguagem oral que de-

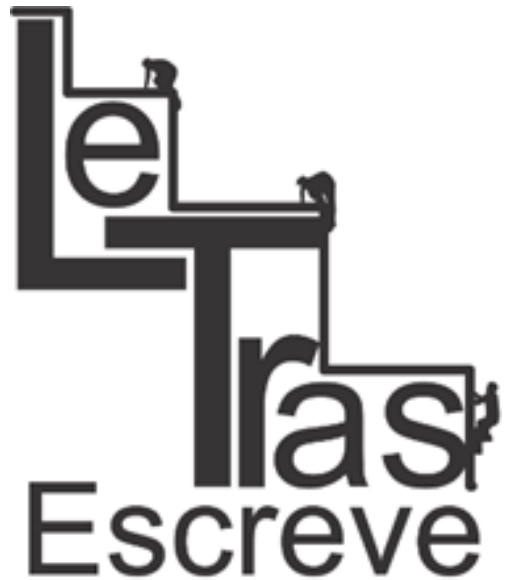

(ISSN 2238-8060) vem ser consideradas, onde a fala dos outros não é somente aquela imediatamente presente, mas é também, aquela proferida em outro momento, mais cedo, por outros não presentes; fala da instituição e de seus membros e representantes. Essas falas podem e devem ser integradas sob uma forma enunciativamente explícita dentro do discurso próprio, onde a estrutura do discurso é o resultado de uma intensa ação recíproca entre gestão local e gestão global do discurso (Schneuwlyet al., 1997. p.5).

Assim, de acordo com Barros-Mendes (2005) essa segunda abordagem, que concebe alinguagem oral como objeto autônomo de ensino,centraliza o trabalho sobre os gêneros da comunicação pública: por um lado, os que servem à aprendizagem escolar, ao mesmo tempo a serviço do ensino da língua materna e de outras disciplinas - exposições, relato de experiências, entrevistas, discussão em grupo etc. - e, por outro, os gêneros da vida pública em sentido amplo do termo, tais como os gêneros dramáticos, o debate, o testemunho diante de uma instância oficial, entre outros.

Ainda de acordo com a estudiosa (2005), a literatura didática e 
de divulgação científica sobre o ensino da linguagem oral tem feito apelos a achados teóricos advindos de várias disciplinas da área dos estudos da linguagem, entre elas a sociolinguística, a psicolinguística, a fonética e a fonologia, a pragmática, a análise conversacional, já que a necessidade de conceber a linguagem oral em objeto autônomo de ensino-aprendizagem implica o conhecimento de suas múltiplas dimensões.

Essas dimensões, conforme a autora, podem ser compreendidas também discursivamente, por meio das características gerais dos gêneros orais do discurso, bem como por meio de um olhar sobre os mecanismos e marcas próprios da fala. Frente ao objetivo geral desse texto, trazem-se descrições breves das dimensões discursivas e materiais da linguagem oral relevantes para o foco do mesmo.

\section{As dimensões da linguagem oral}

Ainda para essa autora, amparada nas reflexões de Dolz (2004) uma das vias para se entender essas dimensões da linguagem oral implica buscar recurso a uma série de campos da linguística, como a (ISSN 2238-8060) fonética, com os elementos que ajudam a compreender os sons da fala e suas características físicas; a fonologia, que auxilia na identificação das características fônicas distintivas da língua e a fono-estilística, que vai esclarecer as variações do ponto de vista da produção e da recepção.

Do ponto de vista dessas disciplinas, a voz é um suporte acústico da fala, do ponto de vista didático, o trabalho com os sons distintivos da língua, o ritmo, a entonação, a acentuação expressiva não implica necessariamente um trabalho acústico isolado. Não se trata de ensinar aos alunos esses saberes, mas sim de tomá-los como suporte para que se tenha uma compreensão devida das diferentes dimen- 
sões integradas nas situações de comunicação trabalhadas, ressalta por fim Dolz (2004).

Desse modo, para abordar condutas orais em toda a sua complexidade, é necessário que se reconheça a existência de uma relação bastante estreita entre os aspectos prosódicos, cinésicos e os aspectos linguístico-discursivos. Daí reside uma grande complexidade e incompreensões sobre como administrar essas dimensões na realidade de ensino efetivo nas salas de aulas, frente a diversidades de situações e atividades que envolvem a linguagem oral.

Dessa situação, Barros-Mendes (2005) considerando os estudos de Dolz (2004) explica que a complexidade de se considerar a linguagem oral como objeto de ensino está no fato desta ser considera-

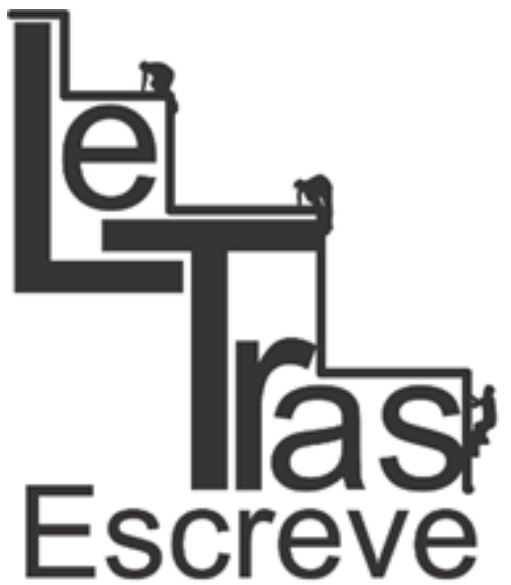

(ISSN 2238-8060) da, ao mesmo tempo, como prática a ser desenvolvida em produção e compreensão pelos alunos e como ferramenta das intervenções dos professores. A problemática reside, fundamentalmente, no fato da linguagem oral ser primariamente concebida como uma ferramenta de mediação e de comunicação, fazendo com que raramente seja considerada como objeto de ensino claramente identificado.

\section{CONCEPÇÕES DO TRABALHO COM O ORAL NA ACADEMIA}

Para atingir o objetivo desse texto que é construir um mapa do trabalho com oral e a partir dele compreender as concepções que circulam na academia acerca do ensino desse objeto, amparados na pesquisa em Linguística Aplicada, lançou-se mão da perspectiva do Paradigma indiciário (Ginsburg, 1992) e Brait (2002), realizou-se um levantamento em sites de diversas universidades públicas e privadas, verificando-se os PPC dos cursos de Letras dessas Instituições. Desse levantamento mapearam-se 39 PPC de Letras. Esse material compreende 19 de Universidades Federais, 10 de estaduais e 8 de particula- 
res.

\section{Descrição dos PPC}

Os PPC, embora de uma mesma licenciatura, Letras, se apresentam bastante diversos quanto a sua organização estrutural e de conteúdo. Além disso, não são todos disponibilizados de forma integral nos sites das Instituições de Ensino Superior (IES). De alguns, foi possível se localizar somente as matrizes, outros apenas os ementários, mas houve aqueles em que se conseguiu de modo completo.

De posse dos PPC e de seus elementos, como ementários, pertinentes para o estudo aqui proposto, se fez um estudo minucioso, tentando enxergar se havia alguma disciplina que se voltasse ao trabalho com os gêneros orais, mais especificamente os formais públicos.

Partindo-se dos dados levantados, construíram-se os gráficos que refletem o mapa sobre como se apresenta a realidade do oral nos PPC de Letras, conforme podemos atestar no gráfico que se segue:

(ISSN 2238-8060)

Gráfico 1: Dos PPCs

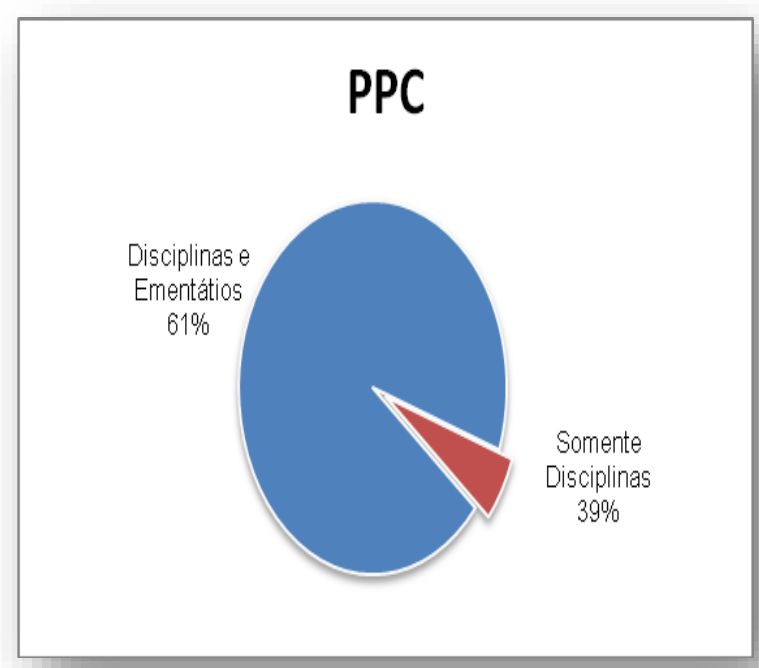


O gráfico acima mostra, de maneira geral, as discplinas e seus ementários, das universidades pesquisadas, e foi comprovado que $61 \%$ trazem uma sinopse dos pontos essenciais do Curso de Letras, em contraponto as demais não contêm este registro escrito, ou seja, disponibilizam somente a matriz curricular.

Gráfico 2: Dos ementários: Atividades com a oralidade.

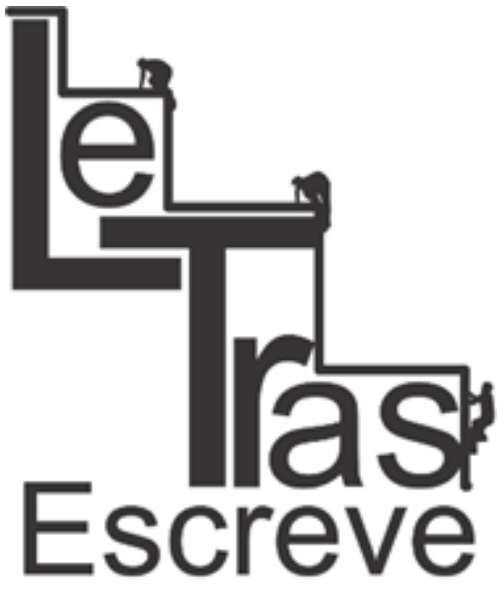

(ISSN 2238-8060)

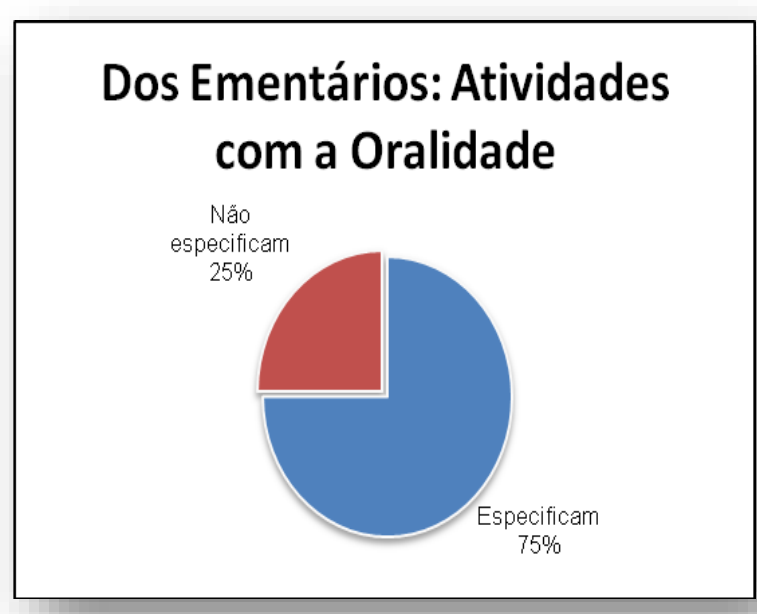

Como se vê, dos 39 ementários dos cursos de Letras $25 \%$ não trazem encaminhamentos de como promover atividade que desenvolvam a oralidade, dessa forma, desses $39,75 \%$ especificam como essas atividades devem ser oportunizadas para que os professores em formação inicial possam adquirir conhecimentos sólidos de como desenvolver o trabalho com a oralidade nas salas de aula das escolas de formação básica, por exemplo:

IES 1: LEITURA E PRODUÇÃO DE TEXTO: Ementa: TrabaIho com estratégias e técnicas de comunicação oral e sobre técnicas de comunicação oral, considerando gêneros textuais diversos

LINGUÍSTICA TEXTUAL: Ementa: Análise de textos orais para o domínio dos processos de coesão e coerência textual na análise de diversos gêneros orais

Como se pode perceber, a IES 1 apresenta o ementário das disciplinas e especifica o que será trabalhado no decorrer destas, apesar

https://periodicos.unifap.br/index.php/letras

Macapá, v. 8, n. 2, 2ㅇ sem., 2018

I8I 
de não especificar quais gêneros serão explorados. Assim, percebe-se que o ensino do oral nas universidades brasileiras, apesar de ser bem considerado e trazer orientações com esse trabalho, ainda, apresenta lacunas.

No que respeita às disciplinas

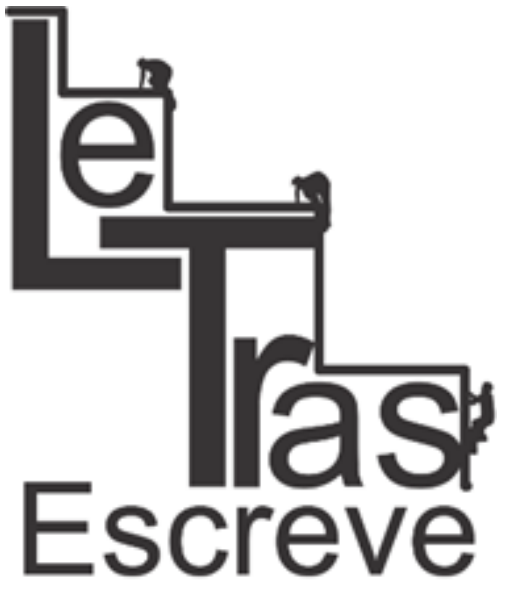

Gráfico 3: Das disciplinas

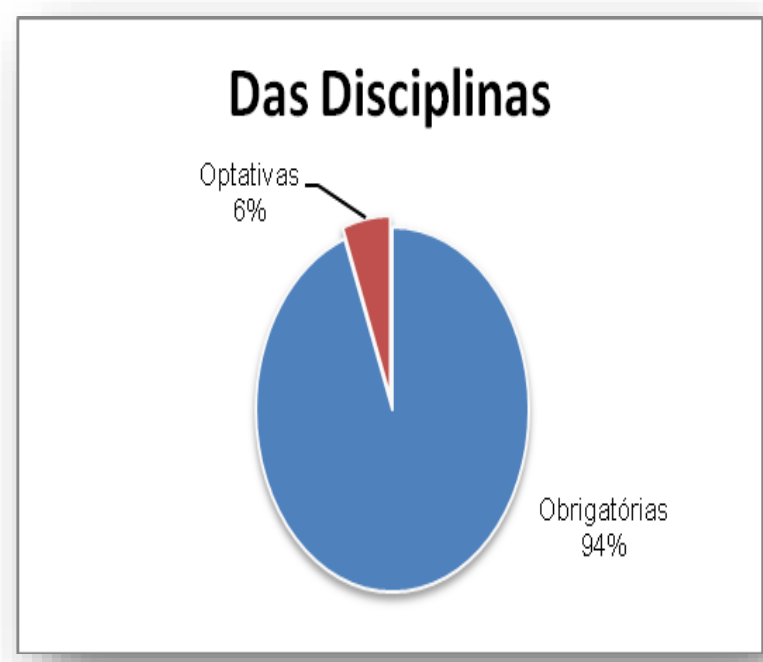

94\% das disciplinas da matriz curricular nas Universidade investigadas citam de maneira superficial, no que diz respeito à oralidade, e assim pode-se afirmar que há lacunas na tomada da (ISSN 2238-8060) linguagem oral como objeto de ensino, e consequentemente estas são deixadas pelo caminho, prejudicando a compreensão sobre o trabalho com orais na interação em sala de aula. Outro ponto, como podemos perceber $6 \%$ portam-se como optativas, ou seja, o graduando tem o poder de escolha em relação às disciplinas ofertadas pelo Curso de Letras.

No que diz respeito aos gêneros orais formais desenhou-se o seguinte gráfico : 


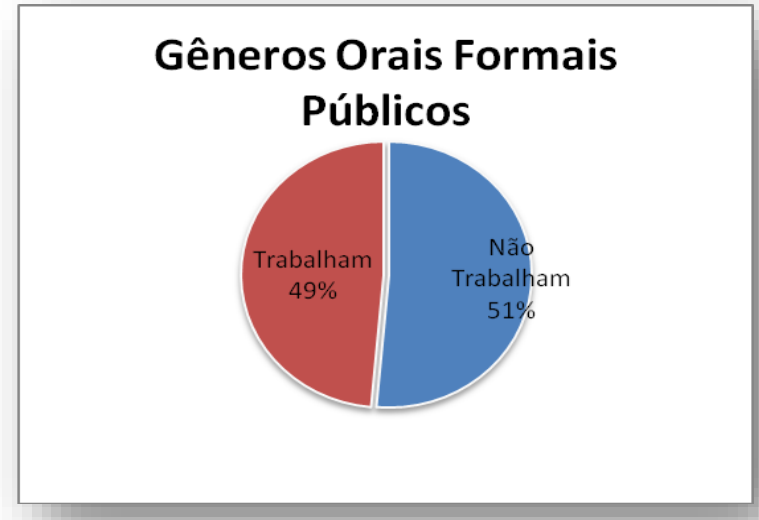

Como pode ser observado no gráfico acima, a porcentagem alcançada na pesquisa sobre os gêneros orais formais e públicos ainda são desafios a serem conquistados nas Universidades do Brasil.

Segundo Bakhtin, os gêneros primários seriam constituídos de

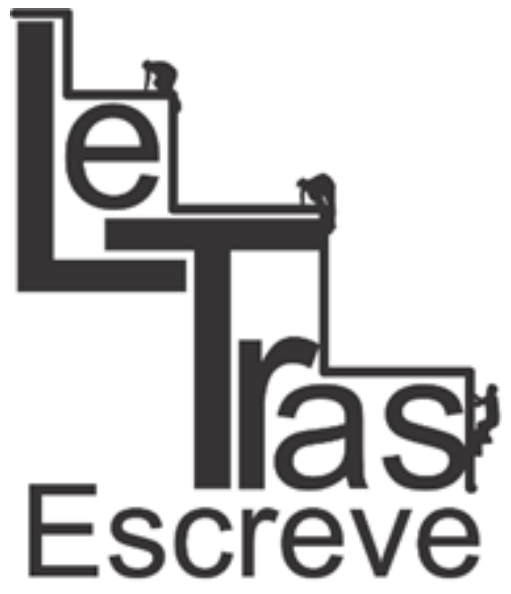

(ISSN 2238-8060) uma comunicação verbal cotidiana/simplória. Já os secundários seriam uma comunicação mais elaborada/complexa do discurso. Acrescenta que os gêneros nos são dados como nos é dada nossa língua materna, ou seja, nós a adquirimos mediante enunciados concretos que ouvimos e reproduzimos durante a comunicação verbal viva que se efetua com indivíduos que nos rodeiam Bakhtin(1952-1953/1979).

A didática de línguas possui uma vasta literatura que dá subsídios para que o professor possa realizar seu papel de formador de sujeitos letrados os quais devem saber utilizar-se da linguagem seja ela na modalidade oral ou escrita, sendo assim a falta de esclarecimento ao adotar os gêneros orais formais públicos como objeto de ensino aprendizagem agrava-se pelo fato de os professores que em formação inicial ao concluírem essa formação terão de atuar na educação básica.

O que se vê é que um ciclo fragilizado de ensino aprendizagem de língua materna está sendo ratificado pelas instituições formadores de agentes de letramento(s), quando verificamos no quadro abaixo que $70 \%$ das IES não deixam claro para seus graduandos que gêneros 
serão tratados no ensino. .

Gráfico 5: Dos que trabalham com gêneros

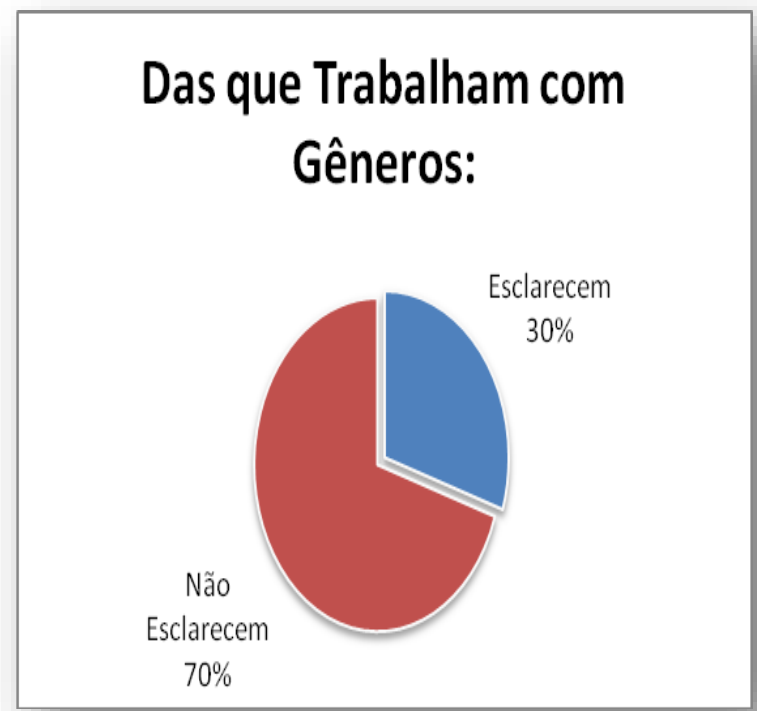

Desse modo, o ensino do oral nas universidades, é pautado em dois modos de se didatizar; ensina-se o oral como meio e como objeto. Pode-se observar no gráfico abaixo que quando as IES trabalham a oralidade como meio, ela é tida como um modo de favorecer a interação dos sujeitos que participam do processo de ensino aprendizagem. Conforme o gráfico 6, 10\% dessas instituições didatizam a oralidade (ISSN 2238-8060) de modo que ela auxilie o professor na aplicação de algum conhecimento linguístico gramatical, ou seja, favorece o professor modos de interagir com os alunos na sala de aula de forma que por meio da interação eles possam vir a compreender os elementos linguístico gramaticais que estão sendo aplicados pelo professor. 


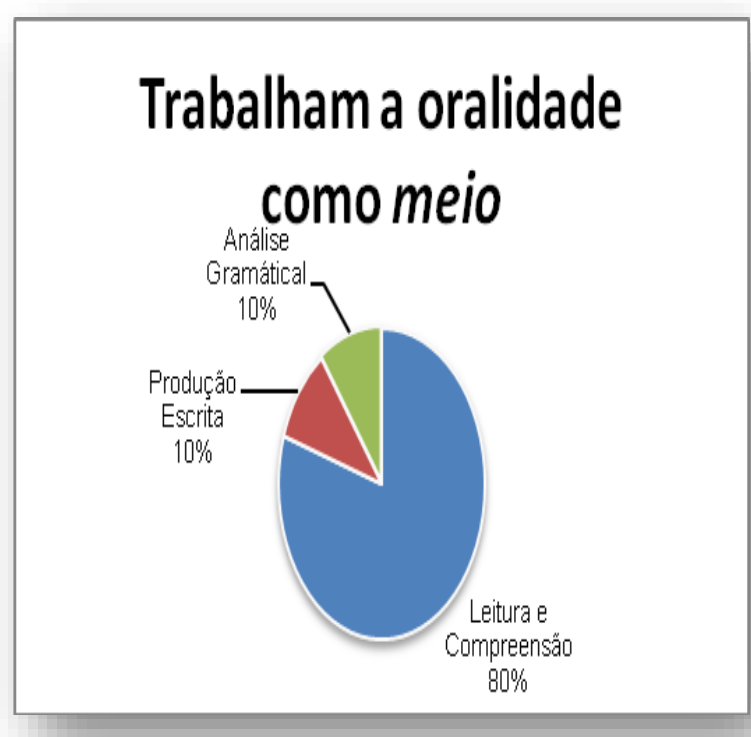

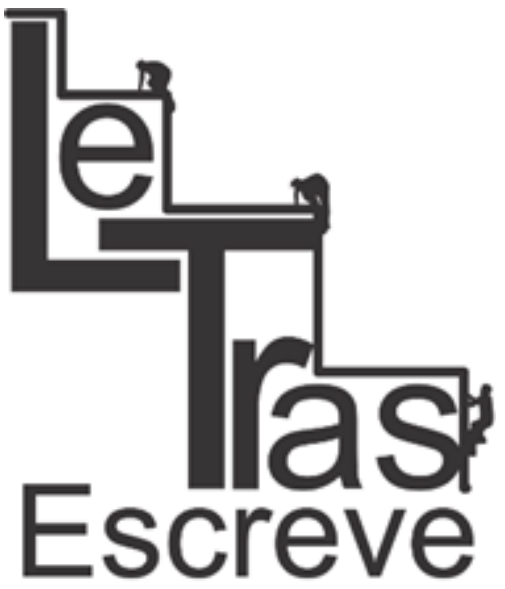

(ISSN 2238-8060)
IES 2: DISCIPLINA: PESQUISA E PRÁTICA DE FORMAÇÃO DOCENTE - Seminários de leitura e produção textual, conhecimentos linguísticos, literatura e expressão oral (p.4)

Também por meio desse gráfico percebe-se que $80 \%$ das instituições utilizam o oral de maneira a favorecer a leitura e a compreensão dos alunos. Nota-se, assim, que o oral didatizado como meio não favorece nenhuma competência nos alunos, isto é, o oral como meio favorece somente condições para o professor conduzir a aula mantendo a interação entre professor/aluno/aluno. Partindo agora para a segunda perspectiva de se didatizar o oral, percebe-se, por meio do gráfico 7, que o oral como objeto é orientado para ser trabalhado por meio de três vertentes: a imersão, a transmissão e a reflexão. Desse modo, infere-se que $50 \%$ das IES partem da imersão, isto é, acreditam que só de proporcionar ao aluno o contato com os gêneros orais 
formais público, o educando irá apropriar-se dos conhecimentos necessários para produzi-los; destacamos novamente que essas instituições não proporcionam ao aluno situações de ensino aprendizagem suficientes para que o alunos possa desenvolver-se como cidadão/profissional apto a produzir textos orais.

Gráfico 7: Dos que trabalham a oralidade como objeto - Perspectivas

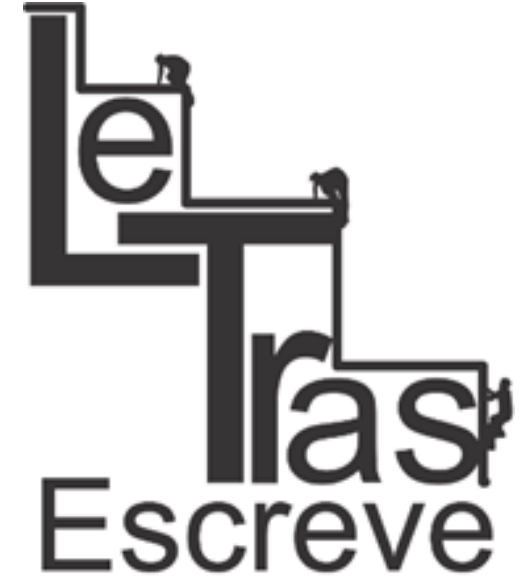

(ISSN 2238-8060)

\section{Trabalham a oralidade como objeto - Perspectivas}

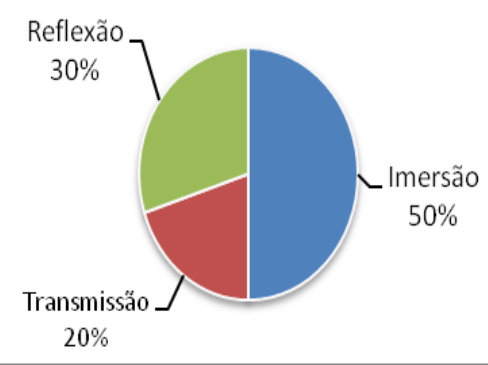

Neste gráfico, infere-se pela forma como é apresentado pelos PPC, que na proposta do trabalho com o oral $20 \%$ dos PPC analisados utilizam a transmissão para ensinar os gêneros orais, ou seja, nessa perspectiva objetiva-se expandir o trabalho com os gêneros orais, pois de acordo com Barros-Mendes (2005, p. 161) por meio dessa perspectiva "transmitem-se alguns elementos envolvidos na construção e compreensão desses gêneros e algumas capacidades de linguagem necessárias para o seu uso são mostradas."

Também de acordo com o gráfico 7, 30\% das IES utilizam a reflexão, ou seja, os alunos irão refletir sobre o gênero oral a ser produzido. Nessa perspectiva o aluno tem a oportunidade de pensar sobre a estrutura do gênero, os elementos linguísticos necessários para a produção dos textos, os interlocutores, isto é, o aluno irá aprender todos os elementos necessários para uma efetiva produção do gênero 


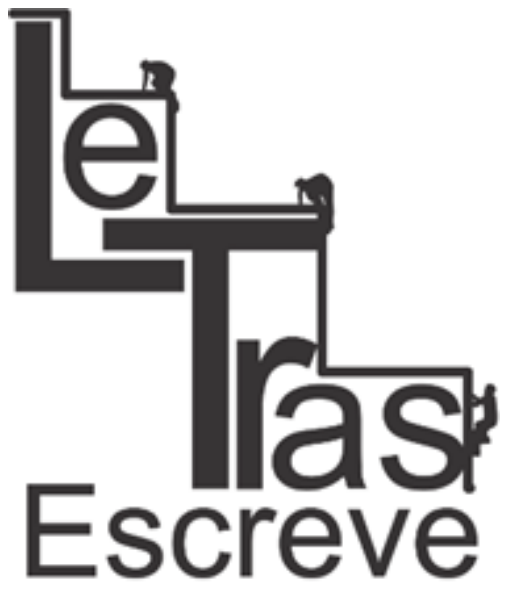

(ISSN 2238-8060)

a ser estudado. Para Barros-Mendes (Op. cit, p. 166) "esse tratamento se diferencia dos demais, porque procura explicitar propriedades do gênero, suas características, processo e estratégias de compreensão e produção. Com isso, aborda um número maior de capacidades de linguagem necessárias para a produção e compreensão dos gêneros orais formais e públicos".

Nesse quantitativo há propostas que promovem o trabalho com a linguagem oral, no entanto, outros objetos são postos priorizados, como a leitura e compreensão textual, a análise linguística e a produção de textos. Há ainda, aquelas em que se dá tratamento mais efetivo à linguagem oral como objeto de ensino-aprendizagem. Assim, há dois grandes modos de tratamento com a linguagem oral: um que trabalha a linguagem oral como meio para a exploração de objetos diversos e outro que visa o ensinodos gêneros orais.

Primeiro Modo: a linguagem oral como meio de exploração de objetos diversos

a) Meio para se trabalhar a leitura e compreensão de textos diversos

Segundo Barros-Mendes (2005), nessa perspectiva, as interações imediatas são priorizadas, o acadêmico pode discutir, expor e argumentar suas ideias, fazer a socialização do assunto trabalhado em sala de aula, assim a oralidade serve de meio para se explorar a leitura e compreensão de textos.

Entendendo que oralidade é utilizada puramente para a compreensão de textos lidos, compreende-se então que o texto escrito é o ponto de partida e de chegada e que a oralidade serve somente para informar seu conteúdo em sala de aula. Essa prática é percebida nos PPC de oito Instituições de Ensino Superior abaixo:

https://periodicos.unifap.br/index.php/letras

Macapá, v. 8, n. 2, 2오. sem., 2018 
Quadro 1: Disciplinas que trabalham a oralidade como meio para leitura e compreensão de textos

\begin{tabular}{|l|l|}
\hline IES & DISCIPLINAS \\
\hline 1 & $\begin{array}{l}\text { DISCIPLINA: PESQUISA E PRÁTICA DE FORMAÇÃO DOCENTE - Seminários de leituras dos } \\
\text { PCNs do Ensino Fundamental e Médio (Pág. 34-35,40) }\end{array}$ \\
\hline 2 & $\begin{array}{l}\text { LEITURA E PRODUÇÃO DE TEXTOS - Oportunizar, ao acadêmico, leitura e reflexão sobre a } \\
\text { prática de leitura e produção textual no ensino fundamental e médio (p. 42,43) }\end{array}$ \\
\hline 3 & $\begin{array}{l}\text { LEITURA E PRODUÇÃO DE TEXTO EM LínGUA PORTUGUESA-Prática de leitura e produção } \\
\text { de texto, de diversos gêneros, em português, fundamentadas no conceito de linguagem } \\
\text { como atividade interlocutiva e no texto como unidade básica significativa na língua (p.27). }\end{array}$ \\
\hline 4 & $\begin{array}{l}\text { LITERATURA DRAMÁTICA 1- Estudo dos gêneros literários e das relações entre literatura e } \\
\text { dramaturgia com base na leitura e análise de textos: a tragédia grega clássica (Ésquilo, } \\
\text { Sófocles e Eurípides) e a comédia de Aristófanes. (p. 49). }\end{array}$ \\
\hline
\end{tabular}

Fonte : Projetos Pedagógicos de Curso

Note-se que nestas disciplinas apresentam-se possibilidades de se desenvolver estratégias expositivas e argumentativas, uma vez que o aluno poderá posicionar-se em sala de aula em relação ao que leu, existirá sim a construção de conhecimentos, tanto individualmen-

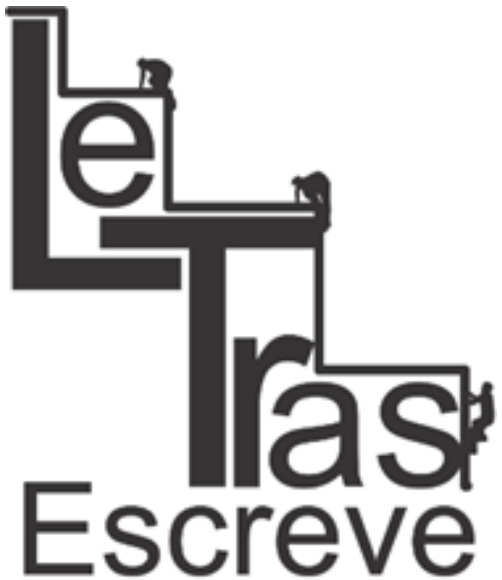

(ISSN 2238-8060)

te quanto em conjunto, por meio da oralidade. Diante disso, é provável que haja interação entre os alunos e o professor, entretanto, é necessário que haja uma maior e melhor sistematização acerca da metodologia utilizada, pois lançar mão somente de situações de comunicação marcada essencialmente por gêneros primários já não é suficiente.

\section{b) Meio para a produção de textos escritos}

Nessa perspectiva, a oralidade é apenas um instrumento que funciona de apoio durante a organização da produção escrita. Segundo Barros-Mendes (2005, p. 149), a oralidade ao ser concebida assim passa a funcionar "como meio, presta-se, especialmente, como auxiliar na elaboração temática". Ou seja, são propostos momentos de verbalização a respeito de um determinado tema para que, em seguida, se possa atingir a finalidade da atividade, que é justamente a produção escrita, como pode-se ver a seguir: 
IES 12: DISCIPLINA: PESQUISA E PRÁTICA DE FORMAÇÃO DOCENTE-Seminários de leitura, produção textual, conhecimentos linguísticos, literatura e expressão oral (pag. 45)

A oralidade tem, também, o papel de mediar a construção de conhecimentos em sala de aula, porém, é importante deixar isso bem claro: a oralidade pode servir como meio e como objeto. É possível promover um trabalho no qual explore a oralidade dos dois modos, mas, sabe-se que dependendo da situação ela será explorada de uma forma ou de outra, o importante é que os acadêmicos tenham total noção disso. Na disciplina acima o trabalho vai sendo desenvolvido com a finalidade de que o acadêmico saiba produzir um projeto científico, para tanto serão promovidos principalmente seminários, porém, apesar de ser uma produção oral, o acadêmico na maior parte das vezes os vê, pois assim é tratado, apenas como meio de construção de conhecimentos acerca de um projeto científico, que é um gênero textual.

\section{c) Meio para exploração de aspectos gramaticais}

(ISSN 2238-8060)

Segundo Barros-Mendes (2005, p.153), nessa abordagem, a "linguagem oral é acionada para as interações em que se vão discutir questões referentes a alguns conhecimentos linguísticos, seja de ordem sintática, semântica ou de ordem lexical", como o objetivo de estabelecer a compreensão acerca dos aspectos linguísticos que contribuem para a construção de sentidos do texto como pode-se ver no exemplo abaixo:

IES 13: GRAMÁTICA TEXTUAL DO PORTUGUÊS - Análise de aspectos textuais-discursivos em textos, falados e escritos, do português. Contribuições dessa análise para o ensino da leitura e da escrita. (pag. 43) 
Ainda de acordo com Barros-Mendes (2005), além, de se explorar elementos linguístico-gramaticais, por meio da oralidade, visto que isso presta um papel importante, pois foge daquela prática descontextualizada vivida em muitas salas de aula, se faz necessário abordá-la como objeto a ser ensinado.

\section{Segundo Modo: a linguagem oral como objeto de ensino}

\section{a) Perspectiva da imersão}

A ideia basilar dessa perspectiva, segundo Barros-Mendes (2005, p. 158), é a de que 'se aprende 'fazendo', entendendo-se que, se se inserir o aluno num processo de imersão nos gêneros (Rojo,

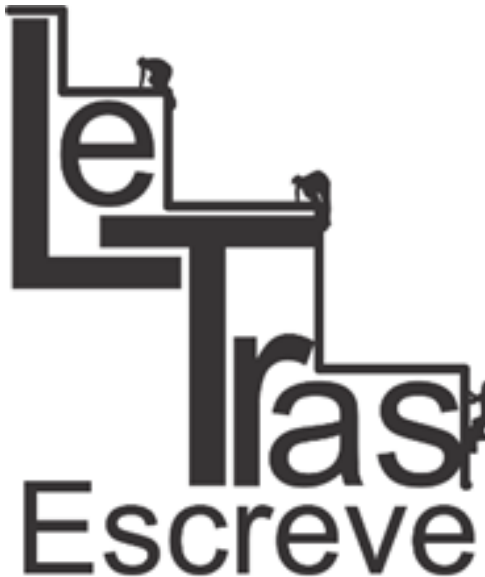

(ISSN 2238-8060) 2005,p.17), ele os dominará pela circunstância do 'fazer'”, ou seja, a prática de ensino e aprendizagem circula no "praticar" em sala de aula, de acordo com a necessidade da situação. Abaixo estão algumas discioplinas de diferentes IESs que dão prioridade à compreensão e produção de gêneros textuais orais:

Quadro 2: Das disciplinas que trabalham a oralidade como objeto de ensino sob a perspectiva da imersão

\begin{tabular}{|l|l|}
\hline IES & DISCIPLINAS \\
\hline 1 & $\begin{array}{l}\text { PRÁTICA DE ANÁLISE LINGÜÍSTICA E DE TEXTOS LITERÁRIOS-Texto, ação e interatividade. } \\
\text { Encenação de texto. A literatura como instrumento de socialização e construção do edu- } \\
\text { cando. A visão de totalidade da literatura no fazer pedagógico. Prática de escuta de textos. } \\
\text { Reflexão de linguagem verbal: prática descritiva, produtiva e prescritiva. (p.59) }\end{array}$ \\
\hline 2 & OFICINA DE EXPRESSAO ORAL (sem ementa) p. 7 \\
\hline 3 & $\begin{array}{l}\text { LEITURA E PRODUÇÃO DE TEXTOS CIENTíFICOS: Elaboraçãode trabalho científico: projeto } \\
\text { para monografia; relatório de pesquisa; artigo científico; ensaio. Seminário. Linguagem e } \\
\text { tecnologiasda informação e da comunicação: a importância dos recursos tecnológicos na } \\
\text { formação e produção do profissional na área de letras. Procedimentos didáticos de utiliza- } \\
\text { ção das tecnologias da informação e comunicação como instrumentos para o ensino- } \\
\text { aprendizagem. (p.39) }\end{array}$ \\
\hline 4 & $\begin{array}{l}\text { LínGUA PORTUGUESA I- Produção de textos orais e escritos, literários e não-literários e de } \\
\text { variedades linguísticas diferentes. (p. 56) }\end{array}$ \\
\hline 5 & $\begin{array}{l}\text { DISCIPLINA ESTÁGIO CURRICULAR SUPERVISIONADO III-Ementa Elaboração de planos de } \\
\text { estudos e instrumentos de avaliação. Regência de aulas de língua portuguesa e literatura } \\
\text { brasileira no ensino fundamental. Elaboração e apresentação de trabalho acadêmico. (p. } \\
54)\end{array}$ \\
\hline 6 & $\begin{array}{l}\text { PRÁTICA DE ANÁLISE LINGÜÍSTICA E DE TEXTOS LITERÁRIOS-Texto, ação e interatividade. } \\
\text { Encenação de texto. A literatura como instrumento de socialização e construção do edu- } \\
\text { cando. A visão de totalidade da literatura no fazer pedagógico. Prática de escuta de textos. } \\
\text { Reflexão de linguagem verbal: prática descritiva, produtiva e prescritiva. (p.59) }\end{array}$ \\
\hline Fonte: Projetos Pedagógicos de Curso
\end{tabular}


É necessário que ao elaborar atividades sobre qualquer que seja o gênero textual oral fiquem explícitos os objetivos dessas atividades, pois, por meio delas é que o acadêmico construirá o conhecimento para distinguir as características relativamente estáveis que Bakhtin tanto apresentou em suas obras, além disso, o acadêmico, futuro professor, construirá essa consciência que será a base do seu trabalho em sala de aula com seus futuros alunos.

\section{b) Perspectiva da transmissão}

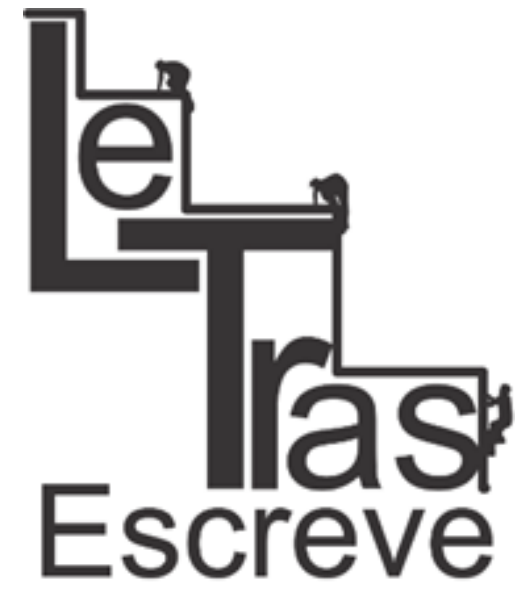

(ISSN 2238-8060)

IES 25: LEITURA E PRODUÇÃO DE TEXTOS - leitura e produção de textos academico-cientificos; Estratégias e técnicas da comunicação oral. Texto e discurso. Técnicas e tecnologias da comunicação oral. A leitura e a produção de textos em sala de aula. Leitura e produção de textos de temáticas ambientais. Habilidades: leitura e produção de textos orais $(p .54,55)$

IES 26 : COMPREENSÃO E PRODUÇÃO DE TEXTOS ACADEMICOS-Leitura e produção de textos, visando a desenvolver habilidades de elaboração de textos acadêmicos orais e escritos. Apresentação de trabalhos acadêmicos.

Percebe-se que na disciplina LEITURA E PRODUÇÃO DE TEXTOSda IES 25 são apresentadas e transmitidas estratégias e técnicas para a produção textual oral. Já na disciplina COMPREENSÃO E PRODUÇÃO DE TEXTOS ACADEMICOS da IES 26 a leitura e produção textal são os meios necessários para o desenvolvimento de habilidades de elaboração de textos orais. Dessa forma, estas duas IES's têm o propósito de estabelecer o ensino de gêneros textuais orais, por meio da transmissão de seus elementos textuais e contextuais 
c) Perspectiva da reflexão - a linguagem oral se apresenta como objeto autônomo de ensino

Essa perspectiva é diferente das demais, pois prioriza apresentar e explorar as expecificidades e propriedades de cada gênero. Dessa feita, aborda com mais precisão os gêneros textuais orais, efetivando, assim, uma abordagem que estabelece uma relação mais aproximada com as estratégias de indução e reflexão (Rojo, 2005, p.17) sobre as situações a serem exploradas, por exemplo:

IES 27: LABORATÓRIO DE TEXTOS CIENTÍFICOS I: (...)seminário. . (p. 41)

IES 28: LEITURA E PRODUÇÃO DE TEXTOS IV- Análise e produção de gêneros discursivos orais. Tópicos de ensino-aprendizagem de gêneros discursivos orais. Prática pedagógica da produção de gêneros discursivos orais. (p.37)

IES 29: PRODUÇÃO TEXTUAL ACADÊMICA I-Estudo seminário. (p.. 13)

Nos exemplos acima, verifica-se que há uma maior preocupação com a produção do gênero textual oral formal público seminário, importante para a esfera em que o acadêmico se encontra, assim ele (ISSN 2238-8060)

poderá refletir melhor acerca do seu uso e funcionalidade.

\section{CONSIDERAÇÕES FINAIS}

Assim, diante da análise feita dos trinta e nove PPC de Letras, verificaram-se perspectivas diversas acerca do tratamento com a linguagem oral, tal análise permitiu uma maior reflexão sobre as possíveis causas da fragilidade desse objeto na educação básica, relacionadas à formação inicial de professores, demonstrando que academia ainda não tem clareza de como tratar esse objeto quanto ao processo de transposição e didatização para os acadêmicos, tampouco unidade 
de compreensão acerca do funcionamento do mesmo.

Diante da análise dos PPCs das 39 IES, chegou-se à conclusão que o problema das lacunas presentes no processo de ensino e aprendizagem na educação básica nasce ainda na academia, pois, apesar de $75 \%$ das IFES apresentarem encaminhamentos acerca do trabalho com o oral, percebe-se que o espaço dedicado à oralidade ainda é lacunar, é necessário que as universidades dediquem disciplinas mais específicas no tratamento com a oralidade, dessa forma estará oferecendo subsídios suficientes para a prática em sala de aula dos futuros professores, além disso, é essencial que a universidade desvincule o aparecimento da oralidade somente através de atividades, como o debate ou apresentação oral (bastante solicitados), ideia bastante presente nos PPCs aqui analisados.

Como já dito, a linguagem oral perpassa por todas as licenciaturas, ela está no cotidiano de todos, é utilizada na maior parte do tempo para atos de comunicação, mas, os acadêmicos de Letras, principalmente, devem saber como trabalhá-la em sala de aula, e mais ainda, precisam refletir acerca de sua importância na vida dos alunos.

(ISSN 2238-8060)

\section{REFERÊNCIAS}

BARROS-MENDES, A. N. N. A linguagem oral nos livros didáticos de língua portuguesa do Ensino Fundamental - 3o e 4a ciclos: algumas reflexões. Doutorado em Lingüística Aplicada e Estudos da Linguagem do Programa de Pós-Graduação em Lingüística Aplicada e Estudos da Linguagem da Pontifícia Universidade Católica de São Paulo. São Paulo: PUC/LAEL, 2005.

BAKHTIN, M. Os gêneros do discurso. IN :Estética da Criação Verbal, São Paulo: Martins Fontes, 1952-53/1979. p. 277-326.

BRAIT, B.PCNs, Gêneros e Ensino de Língua: Faces discursivas da tex- 
tualidade. IN: ROJO, R. H. R. (org) A prática de linguagem em sala de aula: praticando os PCNs, pp.11-20. São Paulo: Educ/ Mercado de Letras, 2001.

BRASIL. Parâmetros Curriculares Nacionais-PCNs/ Língua Portuguesa (3 e 4 ciclos). Brasília, MEC/SEF, 1998.

DOLZ, J. L' oral em didactiquesdufrançais. Um objetirréductibleaux disciplines contributives. IN: CHATELAND,G et al. Unité etPluralitédesSciences de L' éducation. Berne. Peter Lang SA, Editionseuropéennes, 2004.

GINZBURG, C. Mitos, emblemas, sinais. São Paulo: Companhia das Letras, 1991.

ROJO, R. H. R. \& CORDEIRO, G. S. (orgs/trads). Gêneros orais e escritos na escola. Tradução de trabalhos de Schneuwly\&Dolz, pp. 247277. Campinas: Mercado de Letras, 2004.

Documento de Análise da Área de Língua Portuguesa para o ensino Fundamental - PNLD/2007. Relatório apresentado ao Ministério da Educação/SEIF, circulação restrita, 2005.

SCHNEUWLY, B. Palavra e ficcionalização. IN: ROJO, R. H. R. \& CORDEIRO, G. S. (Orgs/trads) (2004) Gêneros orais e escritos na escola. Tra(ISSN 2238-8060) dução de trabalhos de Schneuwly\&Dolz, pp. 129-147. Campinas: Mercado de Letras, 1997 .

Enviado em : 31/01/2017

Aceito em : 14/03/2019 